IZA DP No. 4836

The Impact of Degree Class on the First Destinations of Graduates: A Regression Discontinuity Approach

Giorgio Di Pietro

March 2010 


\title{
The Impact of Degree Class on the First Destinations of Graduates: A Regression Discontinuity Approach
}

\author{
Giorgio Di Pietro \\ University of Westminster \\ and IZA
}

Discussion Paper No. 4836

March 2010

IZA

P.O. Box 7240

53072 Bonn

Germany

Phone: +49-228-3894-0

Fax: +49-228-3894-180

E-mail: iza@iza.org

Any opinions expressed here are those of the author(s) and not those of IZA. Research published in this series may include views on policy, but the institute itself takes no institutional policy positions.

The Institute for the Study of Labor (IZA) in Bonn is a local and virtual international research center and a place of communication between science, politics and business. IZA is an independent nonprofit organization supported by Deutsche Post Foundation. The center is associated with the University of Bonn and offers a stimulating research environment through its international network, workshops and conferences, data service, project support, research visits and doctoral program. IZA engages in (i) original and internationally competitive research in all fields of labor economics, (ii) development of policy concepts, and (iii) dissemination of research results and concepts to the interested public.

IZA Discussion Papers often represent preliminary work and are circulated to encourage discussion. Citation of such a paper should account for its provisional character. A revised version may be available directly from the author. 
IZA Discussion Paper No. 4836

March 2010

\begin{abstract}
The Impact of Degree Class on the First Destinations of Graduates: A Regression Discontinuity Approach

This paper uses a regression-discontinuity design to identify the causal impact of degree class on the first destinations of UK graduates. We exploit the discontinuous relationship between degree class and the mean grade achieved by graduates in their last year at university, which is induced by the administrative rules used for the determination of degree class. More specifically, we compare the average first-destination outcome of graduates with a mean grade that just allowed them to get a given class of degree with the average firstdestination outcome of those with a mean grade that made them just miss the chance of achieving the same class of degree. Our empirical analysis focuses on graduates who graduated from a post-1992 university in the period January-July 2008. The results are consistent with the view that degree class does not truly affect the first destinations of graduates, but it picks up the effect of other ability indicators that are typically not observed by researchers. Hence this finding questions the signaling role of degree class.
\end{abstract}

JEL Classification: $\quad$ 121, J24, J23

Keywords: first destinations of graduates, regression discontinuity design, degree classification

Corresponding author:

Giorgio Di Pietro

University of Westminster

Westminster Business School

Department of Economics and Quantitative Methods

35 Marylebone Road

NW1 5LS London

United Kingdom

E-mail: G.D.I.Pietro@westminster.ac.uk 


\section{Introduction}

Data on the first destinations of graduates of British universities were first released for the academic year 1961/2 and since then have been produced annually. These data are of great interest to prospective students, higher education institutions and the government. As one of the factors affecting the choice of a university course is the employment opportunities after graduation, potential university students are often interested to know which universities successfully place their graduates into jobs. The universities themselves are also keen to find out how their own graduates have performed in the job market relative to other universities. In light of this information, higher education institutions may choose to enhance the quality of their education, research or other services. Finally, data on the first destinations of graduates may satisfy policymakers’ need to improve the accountability of universities.

Numerous studies have shown that several individual characteristics are likely to influence the status of UK graduates six months after leaving university. Purcell and Hogarth (1999) argue that age on graduation is a relevant factor as older graduates generally have poorer employment prospects than their younger peers. Class of degree is also likely to be an important determinant of graduate first-destination outcomes. Recent graduates with a higher class of degree are found to be more likely to engage in further study or employment relative to their peers who have performed less well at university, ceteris paribus. Using data for the cohort of 1993 university leavers, Smith et al. (2000) show that male and female graduates who received a First class degree are, respectively, about 7 per cent and 4 per cent more likely to be in employment or in further study than those with an Upper Second class degree. This result for males is consistent with the findings of Bratti et al. (2004) who employ data for the 1997-1998 cohort of university leavers.

In this paper we attempt to carefully examine the relationship between class of degree and graduate first-destination outcomes. Our aim is to establish whether degree class truly impacts the first destinations of graduates or is simply picking up the effect of unobservables that are correlated with it. The former hypothesis is consistent with the 'Employer Learning with Statistical Discrimination' (EL-SD) model advanced by Altonji and Pierret (2001). This model states that, to deal with the incompleteness of 
information about the quality of workers in the early stages of their careers, firms distinguish among workers on the basis of easily observable characteristics that are correlated with productivity. In this model, education, gender and race may all act as tools for workers to signal their unobserved ability. However, one would expect this signaling role to become less important in the medium/long term as at that period employers would be able to rely on additional information to measure the productivity of workers. One implication of the EL-SD model is that employers may use class of degree in an attempt to differentiate between job candidates who have recently completed university (Ireland et al., 2009). Hence, other things being equal, recent graduates with a higher class of degree are preferred to those with a lower class of degree on the assumption that the former are perceived to have a higher productivity than the latter.

A similar argument can be put forward for universities or colleges offering postgraduate degrees. If, for instance, the demand for a postgraduate course is higher than the available places, these institutions may decide to screen applications on the basis of several criteria, where one of the most important is the student's final degree classification.

On the other hand, it is also possible that firms (higher education institutions) do not need to statistically discriminate among young graduates (potential postgraduate students) on the basis of degree class as they can typically rely on more detailed information about their ability. This view is consistent with the findings of a recent study by Arcidiacono et al. (2008) who find that employers can almost perfectly observe the ability of recent college graduates. This is made possible by the fact that the large majority of resumes of recent college graduates include the results of several academic examinations as well as the scores of various standardized tests. Firms may also acquire additional information on workers' productivity through job interviews and letters of recommendations. Unfortunately, however, most graduate surveys only report information on degree class and they do not comprise other more precise measures of ability. Hence, generally, econometricians do not observe as much productivity information as the firms. The implication of this is that, not only are researchers unable to observe ability indicators considered by employers, but they are also likely to overestimate the effects associated with class of degree. This is because 
degree class may be picking up the effects of the unobserved ability measures on the first destinations of graduates.

This paper addresses the endogenity problem of degree class using a regression discontinuity (RD) approach. The RD design exploits the discontinuous relationship between class of degree and an observed academic ability score. Whilst graduates with a score exceeding a known cutoff point are likely to get a higher class of degree, those with a score below this cutoff point are likely to obtain a lower class of degree. The intuition behind using this research design is to compare the average firstdestination outcome of graduates with a score that just allowed them to get a given class of degree (i.e. treated group) with the average first-destination outcome of those with a score that made them just miss the chance of achieving the same class of degree (i.e. control group). Intuitively, for these two sets of graduates the probability of getting this class of degree (i.e. the treatment) can be basically thought as being randomly assigned. Hence, as the treated group differs from the control group in terms of class of degree obtained but not with respect to academic ability, the difference in their average outcomes allows us to identify the signaling effect exerted by this class of degree on the first destinations of graduates.

The remainder of this paper is as follows. Section 2 describes the econometric approach used to estimate the effect of degree class on the first-destination outcomes of graduates. Section 3 presents the data employed in this study. Section 4 reports and discusses the empirical results. Section 5 concludes.

\section{The Econometric Approach}

Researchers willing to estimate the effect of class of degree on the first destinations of graduates have typically run the following regression on a cross section of graduates

$y_{i}=\beta+\alpha_{1} d_{1 i}+\alpha_{2} d_{2 i}+\alpha_{3} d_{3 i}+z^{\prime} H_{i}+\mu_{i}$

where $y_{i}$ is post-university outcome for graduate i, $H$ is a vector of observable graduate characteristics, $\mu$ represents unobserved determinants of the postuniversity outcome and the $d$ 's are dummies for class of degree. More precisely, 
$d_{1}$ takes the value 1 if the graduate obtained a Lower Second class degree and 0 otherwise; $d_{2}$ takes the value 1 if the graduate obtained an Upper Second class degree and 0 otherwise; and $d_{3}$ takes the value 1 if the graduate obtained a First class degree $^{1}$. The parameters of interest are the $\alpha$ 's, which measure the mean differences in the post-university outcomes between graduates with a Third class degree and their peers who obtained higher classes of degree.

The error term in Equation (1) is likely to be correlated with the $d$ 's as it may capture the effect of unobservables that also affect class of degree. Ignoring this would result in estimates of the $\alpha$ 's that are biased upwards. Nevertheless, addressing this endogeneity issue is not a simple task. For instance, it is hard to use an instrumental variable approach (IV) given the difficulty of finding appropriate instruments, i.e. variables that are correlated with classes of degree but uncorrelated with postuniversity outcome.

In this paper we attempt to account for this endogeneity bias by exploiting discontinuities induced by the administrative rules used for the determination of class of degree. In the UK the primary determinant of final degree classification is the credit-weighted mean of all grades received by the student in his/her final year at university. Students whose mean grade is higher or equal to 40 but less than 50 are likely to obtain a Third class degree; students whose mean grade is higher or equal to 50 but less than 60 are likely to get a Lower Second class degree; students whose mean grade is higher or equal to 60 but less than 70 are likely to get an Upper Second class degree; and finally students whose mean grade is higher or equal to 70 are likely to obtain a First class degree.

Although the mean grade received by students in their final year at university is the chief determinant of the final degree classification, other factors, which are not observed by researchers, play a role too. The Board of Examiners has a discretionary power to raise or to lower the student's final degree classification resulting from the application of the mean grade rule, following the oral recommendations made by its members. Given the non deterministic relationship between class of degree and the

\footnotetext{
${ }^{1}$ Third class degree is the omitted category.
} 
mean grade, the assignment or selection process conforms to that of the so-called fuzzy RD design (Hahn, Todd and van der Klauuw, 2001; van der Klaauw, 2002). It is therefore assumed that the probabilities of obtaining different classes of degree depend on the mean grade with discontinuities at known cutoff values. More precisely, the probability of obtaining a First class degree is a function of the mean grade with a discontinuity at 70. Similarly, the probabilities of obtaining an Upper Second class degree and a Lower Second class degree are a function of the mean grade with discontinuities at 60 and 50, respectively.

It is important to bear in mind that students cannot precisely manipulate the value of their mean grade. As outlined above, this is a weighted average of the grades received by students on the exams taken during their last year at university. Given that the results of these exams are typically released at the same time, it would be unreasonable to think that students are able to calibrate their efforts to achieve an average grade that is just above or equal to a given cutoff point. As a result of this, every student will have approximately the same probability of having a mean grade that is just above or just below a given cutoff value.

In line with the approach of Urquiola and Verhoogen (2009) and Browning and Heinesen (2007), in order to identify the causal effects of degree class on the first destinations of graduates, we adopt a parametric approach. This choice can be justified on the following two grounds. First, we have multiple discontinuities. Second, one rarely has enough observations in the neighborhoods around the cutoff points. Additionally, as noted by Lee and Card (2008), given the discrete nature of the mean grade it would impossible to estimate the degree class effects nonparametrically, even with an infinite amount of data, and therefore one must choose a parametric approach.

We employ a two-stage procedure following the approach of van der Klaauw (2002) and Ferraz and Finan (2008). In the first stage we have three separate treatments or selection rules, one for each degree class dummy included in Equation (1).

$d_{1 i}=E\left(d_{1 i} \mid X_{i}\right)+v_{1 i}=f\left(X_{i}\right)+\tau_{1}^{\prime} H_{i}+\eta_{1} \cdot 1\left\{X_{i} \geq 50\right\}+\eta_{2} \cdot 1\left\{X_{i} \geq 60\right\}+\eta_{3} \cdot 1\left\{X_{i} \geq 70\right\}+v_{1 i}$ $(2-\mathrm{a})$ 
$d_{2 i}=E\left(d_{2 i} \mid X_{i}\right)+v_{2 i}=f\left(X_{i}\right)+\tau_{2}^{\prime} H_{i}+\gamma_{1} \cdot 1\left\{X_{i} \geq 50\right\}+\gamma_{2} \cdot 1\left\{X_{i} \geq 60\right\}+\gamma_{3} \cdot 1\left\{X_{i} \geq 70\right\}+v_{2 i}$ (2-b)

$d_{3 i}=E\left(d_{3 i} \mid X_{i}\right)+v_{3 i}=f\left(X_{i}\right)+\tau_{3}^{\prime} H_{i}+\delta_{1} \cdot 1\left\{X_{i} \geq 50\right\}+\delta_{2} \cdot 1\left\{X_{i} \geq 60\right\}+\delta_{3} \cdot 1\left\{X_{i} \geq 70\right\}+v_{3 i}$ (2-c)

where $X_{i}$ is the credit-weighted mean of all grades received by graduate $\mathrm{i}$ in his/her final year at university; $f($.$) is some function of X$, which is continuous at the cutoff points; 1\{\} is the indicator function- taking the value 1 if the logical condition in brackets holds, 0 otherwise.

In the second stage we include a specification $m(X)$ in the right-hand side of Equation $(1)^{2}$ and replace the endogenous regressors $d$ 's by the fitted values from the firststages i.e. $E\left(d_{1 i} \mid X_{i}\right), E\left(d_{2 i} \mid X_{i}\right)$ and $E\left(d_{3 i} \mid X_{i}\right)$. Hence we have

$y_{i}=m\left(X_{i}\right)+\pi_{1} E\left(d_{1 i} \mid X_{i}\right)+\pi_{2} E\left(d_{2 i} \mid X_{i}\right)+\pi_{3} E\left(d_{3 i} \mid X_{i}\right)+\rho^{\prime} H_{i}+\omega_{i}$

If we assume that $f($.$) and m($.$) have the same functional form, then the two-stage$ estimation procedure is basically equivalent to the two-stage least squares (in case of linear-in-parameter specifications) (van der Klaauw, 2008). In our case there are three excluded instruments, i.e. $1\left\{X_{i} \geq 50\right\}, 1\left\{X_{i} \geq 60\right\}$ and $1\left\{X_{i} \geq 70\right\}$ are included in the first-stage equations but excluded from the post-university outcome equation.

$f($.$) and m($.$) are continuous at the cutoff points { }^{3}$. If these are specified correctly, they capture all dependence of degree class and post-university outcome on the mean grade away from the cutoff points and our IV approach is expected to consistently estimate

\footnotetext{
${ }^{2}$ The idea of including $m(X)$ in the regression of $y$ on the $d$ 's in an attempt to control for selection bias due to selection on observables is known in the econometrics literature as the control function approach (Heckman and Robb, 1985).

${ }^{3} f($.$) and m($.$) are specified as piecewise quadratic functions, i.e.$

$f(X)=m(X)=\psi_{1} X+\psi_{2}(X-50) \cdot 1\{X \geq 50\}+\psi_{3}(X-60) \cdot 1\{X \geq 60\}+\psi_{4}(X-70) \cdot 1\{X \geq 70\}+$

$+\psi_{5} X^{2}+\psi_{6}(X-50)^{2} \cdot 1\{X \geq 50\}+\psi_{7}(X-60)^{2} \cdot 1\{X \geq 60\}+\psi_{8}(X-70)^{2} \cdot 1\{X \geq 70\}$
} 
the $\pi$ 's, effectively employing only the discontinuities in $E\left(d_{1 i} \mid X_{i}\right), E\left(d_{2 i} \mid X_{i}\right)$ and $E\left(d_{3 i} \mid X_{i}\right)$.

\section{Data}

In our empirical analysis, we consider the full cohort of undergraduate students who graduated from a UK post-1992 university in the period 1st January 2008 to 31st July 2008. To construct our data set, we first matched data from the Destination of Leavers from Higher Education (DLHE) survey ${ }^{4}$ with administrative records held by the Higher Education Statistical Agency (HESA). While the latter provide information on several demographic and academic student-level characteristics, the former enables us to track the student's occupation approximately six months after graduation. Finally, from each student's academic history record, we merged into the data set information on the credit-weighted mean grade received by each student in the last year at university.

University student record data are quite rich in the quality of information they give on the personal and academic characteristics of individuals. We have information on gender, date of birth, ethnicity, nationality, disability status, occupation of parent or guardian, final degree classification, academic skills prior to university as measured by UCAS tariff points ${ }^{5}$, subject studied at university, type of term-time accommodation and mode of study (full or part time).

The total number of undergraduate students who graduated from our UK post-1992 university during the period considered here, is 2,773 . Of these, $73 \%$ responded to the DLHE survey, giving a sample of 1,995 graduates. Following Smith et al. (2000) and Bratti et al. (2004), in an attempt to classify post-university outcomes of students six months after graduation, we distinguish between 'positive' outcomes (EFS) and 'negative' outcomes (UOLF). Whilst the former include being in employment (E) or

\footnotetext{
${ }^{4}$ The DLHE survey has previously been known as First Destination Survey (FDS). It is a national statutory survey requiring UK higher education institutions to collect data on behalf of HESA. Information on the status of the university leaver is collected using a standardized questionnaire designed and distributed by HESA.

${ }^{5}$ Tariff points are computed by UCAS to indicate academic equivalence across different academic qualifications (see www.ucas.ac.uk). The system of UCAS tariff points is used by universities and colleges for making offers to applicants.
} 
in further study (FS), the latter comprise being unemployed and seeking work or further study (U) as well as being unavailable for employment or further study (OLF).

In line with the approach used by Angrist (2006) and Kilmer (2007), even though our endogenous variables and our outcome are all binary indicators, we use linear models for every step of our estimation procedure. Heckman and MaCurdy (1985) argue that, in case of simultaneous linear probability models, the IV approach would still deliver consistent coefficient estimates and hence this is a valid technique. Similarly, Angrist (2006) observes that linear 2SLS estimates have a causal interpretation regardless of the possible non-linearity induced by dichotomous dependent variables. Additionally, the consistency of the 2SLS estimates is insensitive to whether or not the first stage conditional expectation function is linear (see Angrist, 2001).

Our first concern lies in the potential bias associated with the selectivity regarding the decision to respond to the DLHE survey. This implies the possibility that unobservable individual characteristics influencing the first-destination outcome are correlated with unmeasured factors driving response to the DLHE survey. In an attempt to address this sample selection issue, we implement a two-step Heckman model using the type of university accommodation as our instrument. As Bratti et al. (2004) note, while this factor is unlikely to affect the status of graduates six months after leaving university, it may have an impact on the probability of responding to the DLHE survey. We estimate an equation for the probability of responding to the DLHE survey, along with a post-university outcome equation for those graduates who responded to the DLHE survey. Our results ${ }^{6}$ show that the estimated correlation between the errors of these two equations is not significantly different from zero. This finding ${ }^{7}$ supports the proposition that the first-destination outcome model (i.e. Equation (1)) can be estimated separately from the DLHE survey response model $^{8}$.

\footnotetext{
${ }^{6}$ Results are available from author upon request.

${ }^{7}$ A bivariate probit model with sample selection was also estimated and the corresponding results show that the errors of the two equations are independent.

${ }^{8}$ As with many similar studies (see, for instance, Naylor et al., 2002), there are two other main sources of potential sample selection bias that unfortunately we are unable to correct for, given the nature of the data. First, there is a selection into university problem. We are unable to model the decision to enroll at university since we do not have information on individuals who did not participate in higher education. Second, there is also a selection issue related to university completion. Once again we cannot address it as we do not have data on students who have dropped out of university.
} 
Of the graduates who responded to the DLHE survey, we remove from the sample those reporting to work for the same employer that they did while they were at university. These graduates are excluded on the basis that they have not experienced any transition from university to work (Bratti and Ballarino, 2009). Additionally, we also exclude from the sample graduates for whom information on the mean grade is unavailable.

Our final sample consists of 1,836 graduates. Summary statistics are depicted in Table 1. Of the graduates included in the final sample, 1,222 were in employment (E), 254 proceeded to further education or training (FS) and 360 were either unemployed and seeking work or further study (U) or inactive- unavailable for employment or further study (OLF) ${ }^{9}$. Unfortunately, information on the UCAS tariff score ${ }^{10}$ and occupation of parent or guardian are unavailable for a large proportion of graduates. However, in order to maximize the sample size, we decided to keep observations with missing values on these variables, and create dummy variables indicating missing status.

\section{Insert Table 1 about here}

Figure 1 shows that class of degree is a discontinuous function of the mean grade received by students in their final year at university. The horizontal lines help us to indentify the relation between these two variables that would be observed if class of degree were exclusively determined by the mean grade. If this was the case, then all graduates achieving a mean grade greater than or equal to 70 would be awarded a First class degree, all those achieving a mean grade greater than or equal to 60 but less than 70 would be awarded an Upper Second degree class, all those achieving a mean grade greater than or equal to 50 but less than 60 would be awarded a Lower Second class degree, and finally all those achieving a mean grade greater than or equal to 40 but less than 50 would be awarded a Third Class degree. The dots (circles) in Figure 1 are actual combinations of classes of degree and the mean grade achieved by graduates in their last year at university.

\section{Insert Figure 1 about here}

\footnotetext{
${ }^{9}$ The proportion of graduates in the OLF category is very similar to that found by Smith et al. (2000).

${ }^{10}$ This is because many students (including international students) enter university without traditional UK qualifications.
} 
However, as shown in Figure 1, the mean grade significantly affects but does not fully explain class of degree. Among those graduates whose mean grade is close to a classification boundary, some are awarded a higher class of degree while others not. As outlined in the previous Section, this depends on the discretionary power of the Board of Examiners which, following the recommendations of its members, may decide to raise the class of degree in borderline cases. On the other hand, although less likely, it is also possible that graduates are awarded a lower class of degree than the one which they would otherwise have been awarded on the basis of the mean grade rule. This occurs if the Board of Examiners judges that the students' performance in their first years at university was remarkably poorer than in the last year. Hence Figure 1 confirms that a "fuzzy" regression discontinuity design with multiple cutoff points and multiple treatments (i.e. classes of degree) is appropriate here.

\section{Empirical results}

Table 2 presents estimates from a linear probability model for graduate firstdestination outcomes. While the first half of Table 2 reports estimates of a basic specification that includes dummies for class of degree as the only explanatory factors in addition to a constant term, the second half of Table 2 shows estimates from a specification that includes all the controls. In both regressions, all the estimated coefficients on the dummies for class of degree, except one, are statistically significant at conventional levels and have the expected positive sign. This finding shows that we are able to reproduce the standard result in the literature- there is a statistically significant relationship in the data between class of degree and postuniversity outcome, with graduates with a higher class of degree being more successful than their peers with a lower class of degree. More specifically, in the less parsimonious specification, graduates who received a First class degree are approximately 22.6 per cent more likely to be in employment or in further study than those with a Third class degree ${ }^{11}$. Although the results on the other explanatory

\footnotetext{
${ }^{11}$ Marginal effects from a logit model are very close to the parameter estimates reported in Table 2. For instance, in the less parsimonious specification the logit model indicates that graduates who got a First class degree are about 22 per cent more likely to be in employment or in further study than those with a Third class degree.
} 
variables are not discussed here, they are broadly consistent with previous similar studies.

\section{Insert Table 2 about here}

However, as discussed earlier, one needs to be cautious about interpreting these results as evidence that degree class has a causal effect on the first destinations of graduates. There are a number of unobserved factors that could be confounding these results. In an attempt to account for the endogeneity bias of class of degree, we implement a RD approach that exploits the discontinuous relationship between class of degree and the mean grade achieved by graduates in their last year at university, which is induced by the administrative rules used for the determination of class of degree. Following van der Klaauw (2002), a first simple exercise consists in examining how the average difference in first-destination outcomes across graduates with two adjacent classes of degree changes if our sample is composed by all graduates who have been awarded one or the other class of degree, as opposed to only include graduates whose mean grade is close to the relevant cutoff value. Results from this exercise are depicted in Table 3.

\section{Insert Table 3 about here}

In the top part of Table 3 we look at the average difference in the first destinations between graduates who obtained a First class degree and those who obtained an Upper Second class degree. When our sample comprises all graduates who received either a First class degree or a an Upper Second class degree, our estimates indicate that the former are about 6.5 per cent more likely to be in employment or in further study (EFS) relative to the latter. However, if this sample is restricted to graduates showing very similar levels of academic ability as measured by the mean grade achieved in their last year at university, this effect disappears. For instance, there is no statistically significant difference in the average EFS probability between First class and Upper Second class graduates if our sample comprises only those graduates whose mean grade is between 71 and 69. A similar result is obtained once we increase 
the width of the interval so that it includes values of the mean grade up to three points above or below $70^{12}$.

In the middle part of Table 3 we examine the average difference in post-university outcomes between graduates who received an Upper Second class degree and their peers who obtained a Lower Second class degree. If the sample includes all graduates who got either an Upper Second class degree or a Lower Second class degree, it turns out that the former are about 6.2 per cent more likely to engage in further study or employment than the latter. Nevertheless, this effect is no longer statistically significant if we only consider graduates whose mean grade is in the neighborhood of 60.

Finally, in the bottom part of Table 3 we compare the average first-destination outcomes between graduates who obtained a Lower Second class degree and those with a Third class degree. Our estimates suggest that the difference in the average EFS probability between these two groups of graduates is not statistically different from zero. This result holds when the sample includes graduates with either a Lower Second class degree or a Third class degree as well as when the sample comprises graduates whose mean grade falls within a narrow interval around 50.

While Table 3 is the first piece of evidence that the RD strategy is likely to generate insignificant results associated with degree class effects, in Figure 2 we plot the EFS probability as a function of the mean grade in an attempt to see whether it exhibits any jump around the three cutoff values. This Figure depicts "raw” mean grade-cell means of the EFS probability ${ }^{13}$ (shown by small circles), along with the fitted values of a locally weighted regression calculated within each mean grade segment (denoted by vertical lines) ${ }^{14}$. Although the EFS probability is an increasing function of the mean grade, no significant jump can be observed around any of the cutoff points. The only remarkable jump seems to take place when the mean grade is around 75 .

\footnotetext{
${ }^{12}$ The relatively large standard errors for these estimates stem from the relatively small sample sizes on which these local estimates are based.

${ }^{13}$ The average EFS probability is computed for each one mean grade interval

${ }^{14}$ The fitted values are from a linear probability model where the EFS probability is a function of the cutoff indicators i.e. $1\left\{X_{i} \geq 50\right\}, 1\left\{X_{i} \geq 60\right\}$, and $1\left\{X_{i} \geq 70\right\}$, a $2^{\text {nd }}$ order polynomial in $X_{i}$ and interactions between the polynomial terms and the cutoff indicators.
} 


\section{Insert Figure 2 about here}

We now implement the IV approach outlined in Section 2. Columns 2 to 4 of Table 4 presents the first-stage estimates from Equations (2-a), (2-b) and (2-c) where each dummy for class of degree is regressed against indicators for whether the mean grade is above the three cutoffs, along with the piecewise quadratic spline for mean grade. The coefficients on the cutoff indicators estimate the average probability of achieving each class of degree at each threshold point. For instance, in column 2 the coefficient on the indicator for the highest cutoff suggests that graduates whose average mark in the last year at university is equal or higher than 70 are approximately 50 per cent more likely to get a First class degree than those whose average mark is lower than $70^{15}$. The value of the F-statistic for each of the three first-stages indicates that there are no-weak instrument problems. A rule of thumb suggested by Bound et al. (1995) and Staiger and Stock (1999) is that the F-statistic should be larger than 10, or at least larger than 5.

\section{Insert Table 4 about here}

Column 5 of Table 4 depicts the corresponding second-stage estimates. Correcting for the endogeneity bias associated with class of degree leads to a significant increase in the size of the standard errors of the coefficients on the dummies for class of degree. This is a common outcome when using a two-stage procedure, where one faces a trade off between inconsistent estimators that have relatively small standard errors (OLS) and consistent but imprecise estimators (IV). The IV estimates show that class of degree has no effect on the first destinations of graduates as all the coefficients on the dummies for class of degree are found not to be statistically different from zero. This result suggests that degree class does not truly influence post-university outcomes, but it is simply picking up the effect of unobserved factors that are correlated with it. Thus, ignoring the correlation between these unobservables and degree class results in estimated coefficients on the dummies for class of degree that are biased upwards. Such a finding is consistent with the view that, while researchers do not observe the true ability measures affecting the first destinations of graduates, they use degree class as a proxy for them.

\footnotetext{
${ }^{15}$ The corresponding marginal effect resulting from a specification where only the cutoff indicators are included is about 90 per cent.
} 
Table 5 depicts the two-stage least squares estimates from a specification that includes all the available controls ${ }^{16}$. These estimates are consistent with those reported in Column 5 of Table 4 as the coefficients on the dummies for class of degree are again found not to be statistically significant.

\section{Insert Table 5 about here}

We perform two robustness tests to check the validity of our results. First, in an attempt to gain precision at the cost of losing information on how the EFS probability varies around each cutoff point, mean grade is recoded into a new variable where we collapse all the three cutoff points into one. This variable takes the value 0 if mean grade is equal to one of the cutoff points (i.e. 50, 60 or 70), otherwise it is equal to the distance of mean grade from the nearest cutoff point. In Figure 3, we replicate Figure 2, this time plotting the EFS probability against the new variable in order to see whether it displays a significant jump around 0. Figure 3 shows that there is no jump in the neighborhood of this cutoff point. In other words, there seems to be no significant difference in the EFS probability between graduates whose mean grade is just above 50,60 or 70 and their peers whose mean grade is just below 50,60 or 70 .

\section{Insert Figure 3 about here}

Second, we revise the IV strategy illustrated in Section 2. Though the same three instruments are employed, in our new IV approach each first stage includes only one instrument (i.e. the indicator for whether the mean grade is above the relevant cutoff) instead of all of them. Hence $1\left\{X_{i} \geq 70\right\}$ is the only instrument included in Equation (2-a); $1\left\{X_{i} \geq 60\right\}$ is the only instrument included in Equation (2-b); and $1\left\{X_{i} \geq 50\right\}$ is the only instrument included in Equation (2-c). 2SLS estimates from this procedure for our basic specification are reported in Table 6. These estimates ${ }^{17}$ clearly indicate that all the coefficients on the dummies for class of degree are not statistically different from zero.

\section{Insert Table 6 about here}

\footnotetext{
${ }^{16}$ The corresponding first-stage estimates are available from author upon request.

${ }^{17}$ The corresponding first-stage estimates are available from author upon request. An IV probit model was also estimates and results were very similar to those reported in Table 6.
} 


\section{Conclusions}

In this paper we examine the effect of degree class on the first destinations of graduates who graduated from a UK post-1992 university in the period January-July 2008. The empirical results suggest that degree class no longer has a significant impact on the probability that a graduate will be in employment or further study six months after graduation, once one controls for the endogeneity of degree class using a regression discontinuity design. This finding may reflect the fact firms and higher education institutions tend to distinguish among recent graduates on the basis of more detailed ability indicators than degree class. For instance, prospective employers and universities typically have access to the resumes of recent graduates, which contain additional information that may help them to have a clearer picture about the ability of graduates.

Given the types of information usually included in survey data sets, researchers are unlikely to be able to observe as much ability information as firms and higher education institutions. The consequence of this is that estimates on degree class may be biased upwards given that degree class is likely to pick up the effects of unobserved ability measures on the first destinations of graduates. This conclusion is especially relevant since the very large majority of econometric studies on labour market outcomes of graduates report estimates of degree class without controlling for the associated endogeneity bias.

Finally, although our findings would seem to question the signaling value of degree class, this does not imply that firms and higher education institutions may not statistically discriminate graduates on the basis of other individual characteristics. Our results simply suggest that the signaling role of degree class is much less important than previously thought. 


\section{References}

Altonji, J.G. and Pierret, C.R. (2001) Employer Learning and Statistical Discrimination', Quarterly Journal of Economics, 116, 313-350.

Angrist J.D. (2006) Instrumental variables methods in experimental criminological research: what, why and how, Journal of Experimental Criminology, 2, 23-44.

Angrist J.D. (2001) Estimation of a limited dependent variable models with dummy endogenous regressors: Simple strategies for empirical practice, Journal of Business and Economic Statistics, 19(1), 2-16.

Arcidiacono, P., Bayer, P. and Hizmo, A. (2008) Beyond signaling and human capital: education and the revelation of ability, NBER Working Paper No. 13951.

Ballarino, G. and Bratti, M . (2009) Field of Study and University Graduates' Early Employment Outcomes in Italy during 1995-2004, LABOUR, 23(3), 421-457.

Bound, J., Jaeger, D.A. and Baker, R.M. (1995) Problems with instrumental variables estimation with correlation between the instruments and the endogenous explanatory variables is weak, Journal of American Statistical Association, 90, 443-450.

Bratti, M., McKnight A.A., Naylor R.A. and Smith, J. (2004) Graduate employability: policy and performance in higher education in the UK, Journal of the Royal Statistical Society (Series A), 167, 475-496.

Browning, M and Heinesen, E. (2007) Class Size, Teacher Hours and Educational Attainment, Scandinavian Journal of Economics,109(2), pages 415-438.

Hahn, J., Todd P. and van der Klaauw W. (2001) Identification and estimation of treatment effects with a regression discontinuity design, Econometrica, 69, 201-209.

Heckman, J.J. and MaCurdy, T.E. (1985) A simultaneous equations linear probability model, Canadian Journal of Economics, 18(1), 28-37.

Heckman, J.J. and Robb, R. (1985) Alternative Methods for Evaluating the Impact of Interventions: An Overview, Journal of Econometrics, 30(1-2), 239-267.

Ireland, N., Naylor, R.A., Smith, J. and Telhaj, S. (2009) Educational returns, ability composition and cohort effects: Theory and evidence for cohorts of early-career UK graduates, CEP Discussion Paper No. 939, July.

Kilmer, B. (2007) Does parolee drug testing influence employment and education outcomes? Evidence from a randomized experiment with noncompliance, Journal of Quantitative Criminology, 24(1), 93-123.

Ferraz, C and Finan, F. (2008) Motivating Politicians: The Impacts of Monetary Incentives on Quality and Performance, IZA Discussion Papers 3411, Institute for the Study of Labor (IZA). 
Lee, D.S. and Card, D. (2008) Regression discontinuity inference with specification error , Journal of Econometrics, 142(2), 655-74.

Naylor, R., Smith, J. and McKnight (2002) Why is there a graduate earnings premium for students from independent school?, Bulletin of Economic Research, 54(4), 315339.

Purcell, K. and Hogarth, T. (1999) Graduate opportunities, social class and age: employers' recruitment strategies in the new graduate labour market, London, Council for Industry and Higher Education.

Smith, J., Naylor, R.A. and McKnight A.A. (2000) Graduate employment outcomes and university performance measures, Economic Journal, Vol. 110, no. 464, F382-411.

Staiger, D. and Stock, J.H. (1997) Instrumental variables regression with weak instruments, Econometrica 65(3), 557-586.

Urquiola, M. and Verhoogen, E. (2009) Class-Size Caps, Sorting, and the Regression Discontinuity Design, American Economic Review, 99(1), 179-215.

van der Klaauw W. (2002) Estimating the effect of financial aid offers on college enrollment: a regression-discontinuity approach, International Economic Review, 43(4), 1249-1287.

van der Klaauw W. (2008) Regression-discontinuity analysis: a survey of recent developments in economics, LABOUR, 22(1), 219-245. 
Table 1

Descriptive statistics

\begin{tabular}{|c|c|c|}
\hline & Mean & Standard Deviation \\
\hline \multicolumn{3}{|l|}{ First-destination outcome } \\
\hline Positive outcome (EFS) & 0.804 & 0.397 \\
\hline Negative outcome (UOLF) & 0.196 & 0.397 \\
\hline \multicolumn{3}{|l|}{ Degree classification } \\
\hline First class & 0.109 & 0.312 \\
\hline Upper second class & 0.486 & 0.500 \\
\hline Lower second class & 0.366 & 0.482 \\
\hline Third class & 0.039 & 0.194 \\
\hline \multicolumn{3}{|l|}{ Gender } \\
\hline Female & 0.612 & 0.488 \\
\hline Male & 0.388 & 0.488 \\
\hline \multicolumn{3}{|l|}{ Nationality } \\
\hline UK & 0.740 & 0.439 \\
\hline Other EU & 0.119 & 0.324 \\
\hline Non-EU & 0.141 & 0.348 \\
\hline \multicolumn{3}{|l|}{ Ethnicity } \\
\hline White & 0.399 & 0.490 \\
\hline Bangladeshi/Indian/Pakistani & 0.275 & 0.446 \\
\hline Black & 0.118 & 0.323 \\
\hline Chinese & 0.015 & 0.123 \\
\hline Other Asian & 0.036 & 0.186 \\
\hline Others/Unknown & 0.157 & 0.364 \\
\hline \multicolumn{3}{|l|}{ Subject studied at university } \\
\hline Law & 0.090 & 0.287 \\
\hline Business & 0.209 & 0.407 \\
\hline Social studies & 0.098 & 0.297 \\
\hline Media, Art and Design & 0.178 & 0.383 \\
\hline Biology & 0.078 & 0.268 \\
\hline Computer Science & 0.104 & 0.305 \\
\hline Languages and Humanities & 0.105 & 0.307 \\
\hline Architecture and the Built Environment & 0.103 & 0.304 \\
\hline Health & 0.035 & 0.185 \\
\hline \multicolumn{3}{|l|}{ Mode of study } \\
\hline Full-time & 0.786 & 0.410 \\
\hline Part-time & 0.214 & 0.410 \\
\hline \multicolumn{3}{|l|}{ Disability status } \\
\hline No disability & 0.948 & 0.223 \\
\hline Disability & 0.052 & 0.223 \\
\hline Age (years) & 25.191 & 6.313 \\
\hline \multicolumn{3}{|l|}{ UCAS Tariff Score } \\
\hline High score $(=$ or $>350)$ & 0.092 & 0.289 \\
\hline Medium score $(>200$ but $<350$ ) & 0.320 & 0.467 \\
\hline Low score $(<$ or $=200)$ & 0.202 & 0.402 \\
\hline Unknown & 0.386 & 0.487 \\
\hline \multicolumn{3}{|l|}{ Socio-Economic Background } \\
\hline High & 0.253 & 0.435 \\
\hline Intermediate & 0.180 & 0.385 \\
\hline Low & 0.111 & 0.314 \\
\hline Unknown & 0.456 & 0.498 \\
\hline Mean grade in the last year at university & 61.181 & 41.429 \\
\hline Number of observations & 1,836 & \\
\hline
\end{tabular}


Figure 1

Degree classes and the mean grade obtained during the last year at university

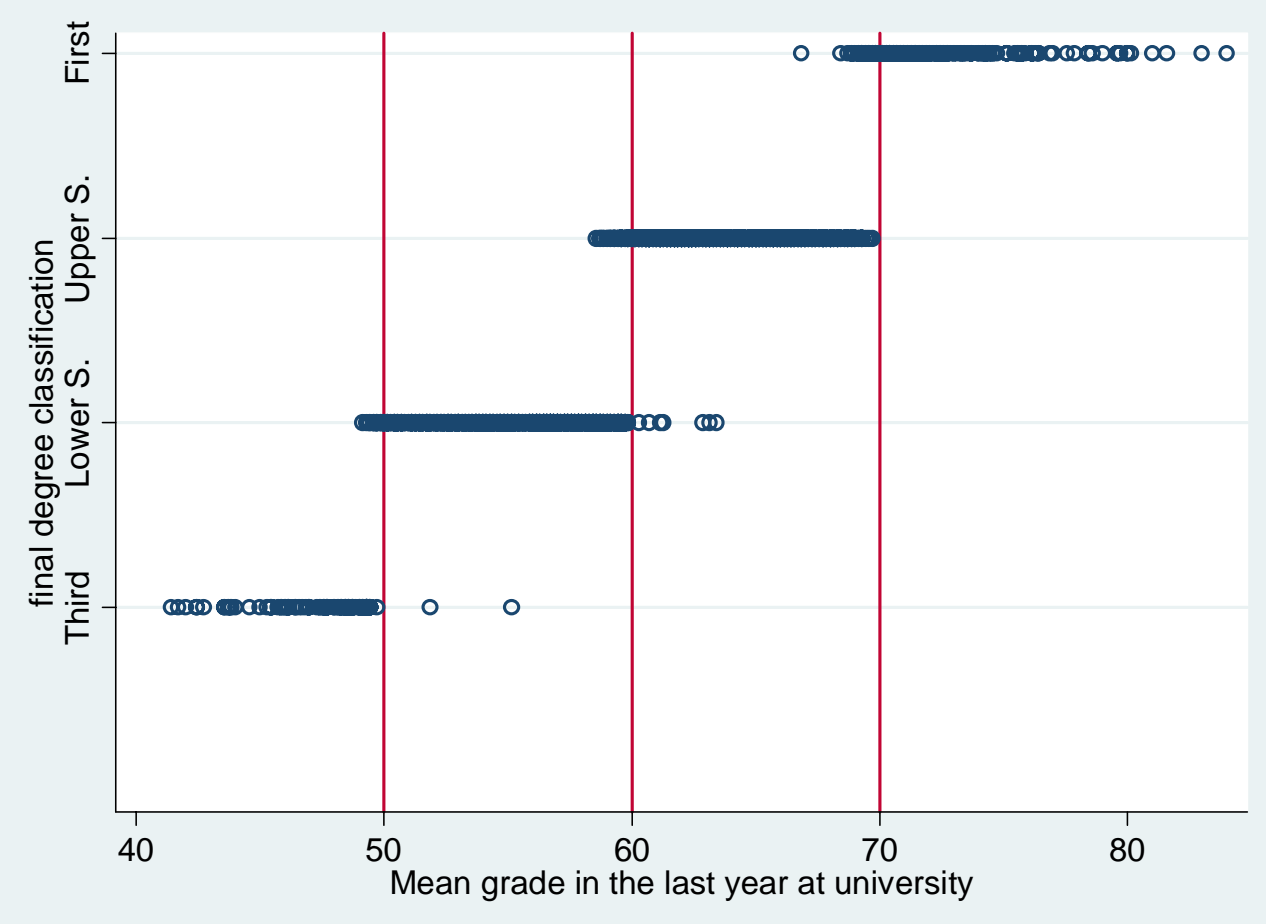


Table 2

Marginal effects on the probability of being in employment or further study (EFS) LPM

\begin{tabular}{|c|c|c|}
\hline & Estimate & Estimate \\
\hline Constant & $0.681 * * *(0.055)$ & $0.808 * * *(0.091)$ \\
\hline \multicolumn{3}{|c|}{ Degree classification- Reference category is Third class } \\
\hline First class & $0.209 * * *(0.059)$ & $0.226 * * *(0.060)$ \\
\hline Upper second class & $0.145 * * *(0.056)$ & $0.153^{* * *}(0.058)$ \\
\hline Lower second class & $0.082(0.057)$ & $0.097 *(0.057)$ \\
\hline female & & $0.007(0.021)$ \\
\hline \multicolumn{3}{|l|}{ Nationality-Reference category is Non-EU } \\
\hline UK & & $0.062 * *(0.031)$ \\
\hline Other EU & & $0.095 * *(0.040)$ \\
\hline \multicolumn{3}{|l|}{ Ethnicity-Reference category is White } \\
\hline Bangladeshi/Indian/Pakistani & & $-0.007(0.027)$ \\
\hline Black & & $-0.023(0.034)$ \\
\hline Chinese & & $-0.131(0.090)$ \\
\hline Other Asian & & $-0.071(0.060)$ \\
\hline Others/Unknown & & $-0.046(0.029)$ \\
\hline \multicolumn{3}{|c|}{ Subject studied at university- Reference category is Business } \\
\hline Law & & $0.132 * * *(0.033)$ \\
\hline Social studies & & $0.010(0.038)$ \\
\hline Media, Art and Design & & $0.026(0.033)$ \\
\hline Biology & & $0.039(0.040)$ \\
\hline Computer Science & & $0.003(0.041)$ \\
\hline Languages and Humanities & & $0.054(0.035)$ \\
\hline Architecture and the Built Environment & & $0.026(0.037)$ \\
\hline Health & & $0.096(0.062)$ \\
\hline Full-time & & $-0.083 * * *(0.025)$ \\
\hline Disability & & $-0.019(0.043)$ \\
\hline Age (years) & & $-0.005 * * *(0.002)$ \\
\hline \multicolumn{3}{|c|}{ UCAS Tariff Score- Reference category is High score $(=$ or $>350)$} \\
\hline Medium score ( $>200$ but $<350$ ) & & $-0.018(0.033)$ \\
\hline Low score $(<$ or $=200)$ & & $-0.033(0.039)$ \\
\hline Unknown & & $-0.010(0.036)$ \\
\hline \multicolumn{3}{|c|}{ Socio-Economic Background-Reference category is High } \\
\hline Intermediate & & $0.007(0.0028)$ \\
\hline Low & & $0.008(0.0034)$ \\
\hline Unknown & & $-0.005(0.024)$ \\
\hline R-squared & 0.014 & 0.043 \\
\hline Observations & 1,836 & 1,836 \\
\hline
\end{tabular}

Standard errors are in brackets

*** denotes statistical significance at 1 per cent

** denotes statistical significance at 5 per cent

* denotes statistical significance at 10 per cent 
Table 3

Local Wald estimates of degree class effects on the probability of being in employment or further study (EFS)

\begin{tabular}{lccc}
\hline & Estimate & Std Error & Obs \\
\hline & First class/Upper second class & \\
Full sample & $0.065^{* *}$ & 0.029 & 1,093 \\
1-point interval around 70 & -0.118 & 0.098 & 96 \\
2-point interval around 70 & -0.003 & 0.049 & 186 \\
3-point interval around 70 & 0.001 & 0.037 & 288 \\
& Upper second class /Lower second class & \\
Full sample & $0.062^{* * *}$ & 0.020 & 1,564 \\
1-point interval around 60 & 0.020 & 0.068 & 189 \\
2-point interval around 60 & 0.006 & 0.043 & 395 \\
3-point interval around 60 & 0.016 & 0.035 & 598 \\
& Lower second class /Third class & \\
Full sample & 0.082 & 0.053 & 743 \\
1-point interval around 50 & -0.041 & 0.143 & 63 \\
2-point interval around 50 & -0.025 & 0.092 & 123 \\
3-point interval around 50 & -0.035 & 0.081 & 170 \\
\hline *** denotes statistical significance at 1 per cent & & \\
$* *$ & denotes statistical significance at 5 per cent
\end{tabular}


Figure 2

Probability of being in employment or further study (EFS) and mean grade in the last year at university

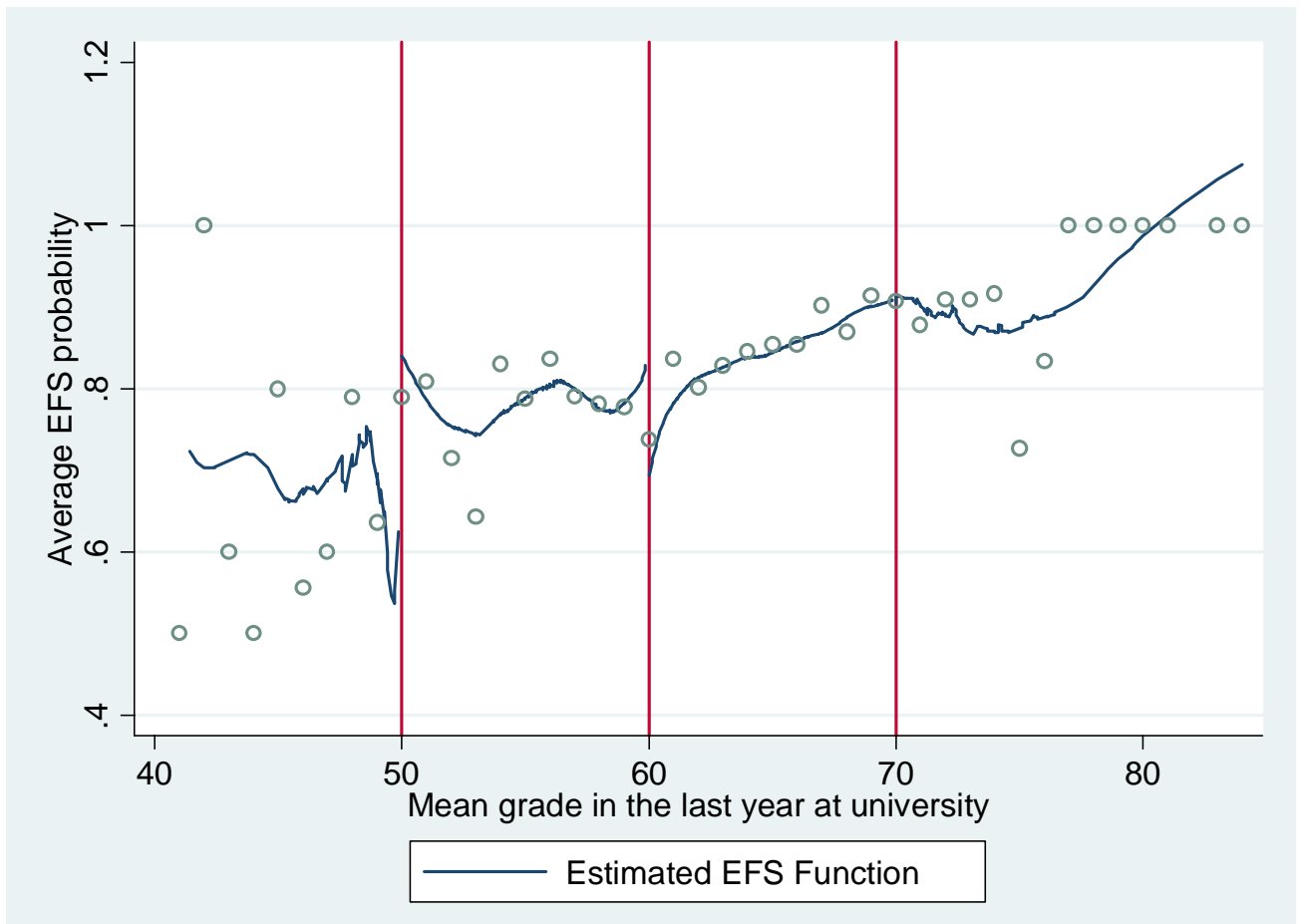


Table 4

First-stages and basic IV specification: Marginal effects on the probability of being in employment or further study (EFS)

\begin{tabular}{|c|c|c|c|c|}
\hline & & First stage & & IV \\
\hline & $\begin{array}{c}\text { First class } \\
\text { degree }\end{array}$ & $\begin{array}{l}\text { Upper second } \\
\text { class degree }\end{array}$ & $\begin{array}{l}\text { Lower second } \\
\text { class degree }\end{array}$ & EFS \\
\hline Constant & $\begin{array}{c}0.002 \\
(5.469)\end{array}$ & $\begin{array}{c}0.005 \\
(8.418)\end{array}$ & $\begin{array}{c}58.415 * * * \\
(7.201)\end{array}$ & $\begin{array}{l}-13.022 \\
(29.158)\end{array}$ \\
\hline $1\{X \geq 50\}$ & $\begin{array}{c}-0.00001 \\
(0.033)\end{array}$ & $\begin{array}{r}0.109 * * \\
(0.050)\end{array}$ & $\begin{array}{c}0.331^{* * * *} \\
(0.043)\end{array}$ & \\
\hline $1\{X \geq 60\}$ & $\begin{array}{c}0.111^{* * *} \\
(0.016)\end{array}$ & $\begin{array}{c}0.561 * * * \\
(0.025)\end{array}$ & $\begin{array}{c}-0.674 * * * \\
(0.022)\end{array}$ & \\
\hline $1\{X \geq 70\}$ & $\begin{array}{c}0.499 * * * \\
(0.022)\end{array}$ & $\begin{array}{c}-0.500 * * * \\
(0.034)\end{array}$ & $\begin{array}{c}0.001 \\
(0.029)\end{array}$ & \\
\hline$X$ & $\begin{array}{r}-0.0001 \\
(0.237)\end{array}$ & $\begin{array}{l}-0.0002 \\
(0.364)\end{array}$ & $\begin{array}{l}-2.597 * * * \\
(0.312)\end{array}$ & $\begin{array}{c}0.618 \\
(1.282)\end{array}$ \\
\hline$(X-50) \cdot 1\{X \geq 50\}$ & $\begin{array}{c}-0.00001 \\
(0.021)\end{array}$ & $\begin{array}{c}-0.082 * * \\
(0.032)\end{array}$ & $\begin{array}{c}-0.201 * * * \\
(0.028)\end{array}$ & $\begin{array}{c}0.087 \\
(0.122)\end{array}$ \\
\hline$(X-60) \cdot 1\{X \geq 60\}$ & $\begin{array}{c}-0.099 * * * \\
(0.008)\end{array}$ & $\begin{array}{l}-0.019 \\
(0.013)\end{array}$ & $\begin{array}{c}0.116^{* * *} \\
(0.011)\end{array}$ & $\begin{array}{c}0.023 \\
(0.034)\end{array}$ \\
\hline$(X-70) \cdot 1\{X \geq 70\}$ & $\begin{array}{c}-0.177^{* * *} \\
(0.011)\end{array}$ & $\begin{array}{c}0.177 * * * \\
(0.017)\end{array}$ & $\begin{array}{c}-0.00004 \\
(0.015)\end{array}$ & $\begin{array}{l}-0.022 \\
(0.042)\end{array}$ \\
\hline$X^{2}$ & $\begin{array}{c}0.000001 \\
(0.003)\end{array}$ & $\begin{array}{c}0.000002 \\
(0.004)\end{array}$ & $\begin{array}{c}0.029 * * * \\
(0.003)\end{array}$ & $\begin{array}{l}-0.007 \\
(0.014)\end{array}$ \\
\hline$(X-50)^{2} \cdot 1\{X \geq 50\}$ & $\begin{array}{c}-0.000001 \\
(0.003)\end{array}$ & $\begin{array}{l}0.010^{* *} \\
(0.004)\end{array}$ & $\begin{array}{c}-0.039 * * * \\
(0.003)\end{array}$ & $\begin{array}{c}0.007 \\
(0.015)\end{array}$ \\
\hline$(X-60)^{2} \cdot 1\{X \geq 60\}$ & $\begin{array}{c}0.014^{* * *} \\
(0.001)\end{array}$ & $\begin{array}{c}-0.024 * * * \\
(0.001)\end{array}$ & $\begin{array}{c}0.010^{* * *} \\
(0.001)\end{array}$ & $\begin{array}{l}-0.002 \\
(0.005)\end{array}$ \\
\hline$(X-70)^{2} \cdot 1\{X \geq 70\}$ & $\begin{array}{c}-0.014 * * * \\
(0.001)\end{array}$ & $\begin{array}{c}0.014 * * * \\
(0.002)\end{array}$ & $\begin{array}{l}-0.0002 \\
(0.001)\end{array}$ & $\begin{array}{c}0.004 \\
(0.005)\end{array}$ \\
\hline \multicolumn{5}{|c|}{ Degree classification- Reference category is Third class } \\
\hline First class & & & & $\begin{array}{c}0.277 \\
(0.275)\end{array}$ \\
\hline Upper second class & & & & $\begin{array}{c}0.237 \\
(0.249)\end{array}$ \\
\hline Lower second class & & & & $\begin{array}{c}0.287 \\
(0.250)\end{array}$ \\
\hline F-statistic & 205.52 & 213.21 & 336.87 & \\
\hline Observations & 1,836 & 1,836 & 1,836 & 1,836 \\
\hline
\end{tabular}

Standard errors are in brackets

*** denotes statistical significance at 1 per cent

** denotes statistical significance at 5 per cent

* denotes statistical significance at 10 per cent 
Table 5

Full control IV specification: Marginal effects on the probability of being in employment or further study (EFS)

\begin{tabular}{|c|c|c|}
\hline & Estimate & Std Error \\
\hline Constant & -16.841 & 29.052 \\
\hline$X$ & 0.790 & 1.277 \\
\hline$(X-50) \cdot 1\{X \geq 50\}$ & 0.098 & 0.122 \\
\hline$(X-60) \cdot 1\{X \geq 60\}$ & 0.029 & 0.034 \\
\hline$(X-70) \cdot 1\{X \geq 70\}$ & -0.015 & 0.042 \\
\hline$X^{2}$ & -0.009 & 0.014 \\
\hline$(X-50)^{2} \cdot 1\{X \geq 50\}$ & 0.009 & 0.015 \\
\hline$(X-60)^{2} \cdot 1\{X \geq 60\}$ & -0.002 & 0.005 \\
\hline$(X-70)^{2} \cdot 1\{X \geq 70\}$ & 0.005 & 0.005 \\
\hline \multicolumn{3}{|c|}{ Degree classification- Reference category is Third class } \\
\hline First class & 0.292 & 0.274 \\
\hline Upper second class & 0.241 & 0.248 \\
\hline Lower second class & 0.300 & 0.250 \\
\hline female & 0.005 & 0.020 \\
\hline \multicolumn{3}{|l|}{ Nationality-Reference category is Non-EU } \\
\hline UK & $0.062 * *$ & 0.029 \\
\hline Other EU & $0.092 * *$ & 0.039 \\
\hline \multicolumn{3}{|l|}{ Ethnicity-Reference category is White } \\
\hline Bangladeshi/Indian/Pakistani & 0.002 & 0.028 \\
\hline Black & -0.014 & 0.033 \\
\hline Chinese & $-0.129 *$ & 0.076 \\
\hline Other Asian & -0.051 & 0.053 \\
\hline Others/Unknown & -0.039 & 0.028 \\
\hline \multicolumn{3}{|c|}{ Subject studied at university- Reference category is Business } \\
\hline Law & $0.134 * * *$ & 0.037 \\
\hline Social studies & 0.006 & 0.036 \\
\hline Media, Art and Design & 0.015 & 0.033 \\
\hline Biology & 0.037 & 0.039 \\
\hline Computer Science & -0.004 & 0.037 \\
\hline Languages and Humanities & 0.048 & 0.036 \\
\hline Architecture and the Built Environment & 0.023 & 0.036 \\
\hline Health & 0.092 & 0.059 \\
\hline Full-time & $-0.094 * * *$ & 0.026 \\
\hline Disability & -0.019 & 0.042 \\
\hline Age (years) & $-0.006 * * *$ & 0.002 \\
\hline \multicolumn{3}{|c|}{ UCAS Tariff Score- Reference category is High score $(=$ or $>350)$} \\
\hline Medium score $(>200$ but $<350$ ) & -0.012 & 0.036 \\
\hline Low score $(<$ or $=200)$ & -0.023 & 0.041 \\
\hline Unknown & 0.0003 & 0.039 \\
\hline \multicolumn{3}{|c|}{ Socio-Economic Background-Reference category is High } \\
\hline Intermediate & 0.001 & 0.029 \\
\hline Low & 0.006 & 0.034 \\
\hline Unknown & -0.008 & 0.024 \\
\hline Observations & \multicolumn{2}{|c|}{1,836} \\
\hline
\end{tabular}

Standard errors are in brackets

*** denotes statistical significance at 1 per cent

** denotes statistical significance at 5 per cent

* denotes statistical significance at 10 per cent 
Figure 3

Probability of being in employment or further study (EFS) and distance from the nearest cutoff value of the mean grade in the last year at university

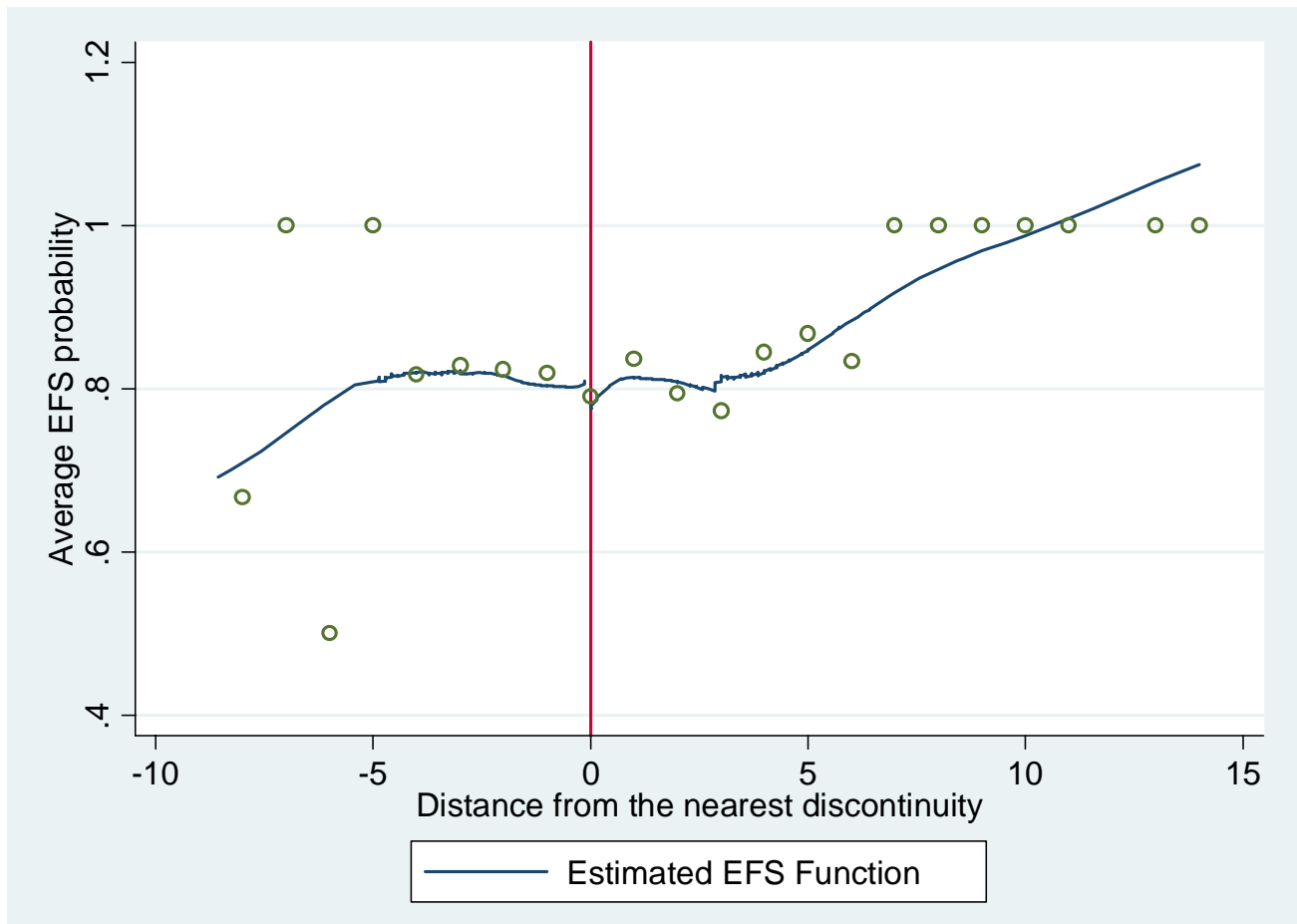


Table 6

Revised IV strategy- Basic IV specification: Marginal effects on the probability of being in employment or further study (EFS)

\begin{tabular}{lcc}
\hline & Estimate & Std Error \\
\hline Constant & -42.247 & 68.268 \\
$X$ & 1.922 & 3.021 \\
$(X-50) \cdot 1\{X \geq 50\}$ & 0.064 & 0.144 \\
$(X-60) \cdot 1\{X \geq 60\}$ & -0.098 & 0.146 \\
$(X-70) \cdot 1\{X \geq 70\}$ & 0.076 & 0.110 \\
$X{ }^{2}$ & -0.021 & 0.033 \\
$(X-50)^{2} \cdot 1\{X \geq 50\}$ & 0.041 & 0.055 \\
$(X-60)^{2} \cdot 1\{X \geq 60\}$ & -0.030 & 0.032 \\
$(X-70)^{2} \cdot 1\{X \geq 70\}$ & 0.012 & 0.009 \\
Degree classification- Reference category is Third class & \\
First class & 0.038 & 0.111 \\
Upper second class & -0.059 & 0.114 \\
Lower second class & 0.798 & 0.864 \\
Observations & & \\
\hline Standard & & \\
\hline
\end{tabular}

Standard errors have been bootstrapped (using 500 replications)

*** denotes statistical significance at 1 per cent

** denotes statistical significance at 5 per cent

* denotes statistical significance at 10 per cent 